\title{
ONTOLOGIA DA PRIVACIDADE
}

PRIVACY ONTOLOGY

\author{
STHÉFANO BRUNO SANTOS DIVINO ${ }^{1}$
}

\section{RESUMO}

O problema de pesquisa deste artigo é o seguinte questionamento: qual é a ontologia da privacidade? Duas propostas serão analisadas. A primeira proposta classifica a privacidade como direito da personalidade. A segunda proposta entende a privacidade como bem disponível, passível de economicidade. Ambas serão analisadas de forma comparativa à luz dos direitos da personalidade e de legislações de proteção de dados. Verifica-se, também, a compatibilidade do entendimento contemporâneo de privacidade com seus aspectos históricos e culturais que a constituíram. Assim, a primeira seção aborda histórica e brevemente o desenvolvimento e origem da privacidade. A segunda seção verifica a adequação dos resultados obtidos na primeira seção e sua adequação às características jurídicas atribuídas aos direitos da personalidade, em especial a privacidade. Ao final, verifica-se que os elementos identificadores de um direito da personalidade são incompatíveis e inverificáveis quando se comparados com a ontologia da privacidade, já que constituída e moldada conforme os preceitos culturais e sociais vigentes à época de seu exercício. Para a construção desse raciocínio, utiliza-se o método dedutivo e a técnica de pesquisa bibliográfica.

PALAVRAS-CHAVE: Privacidade. Ontologia. Personalidade. Dados pessoais.

\section{ABSTRACT}

The research problem with this article is the following question: What is the privacy ontology? Two proposals will be analyzed. The first proposal classifies privacy as personality right. The second proposal understands privacy as a property. Both will be analyzed comparatively from the perspective of personality rights and data protection laws. The contemporary understanding of privacy is also compatible with its historical and cultural aspects. Thus, the first section deals historically and briefly with the development and origin of privacy. The second section verifies the adequacy of the results obtained in the first section and their adequacy to the legal characteristics attributed to personality rights, especially privacy. In the end, it is verified that the identifying elements of a personality right are incompatible and unchangeable when compared with the ontology of privacy since it is constituted and shaped according to the cultural and social precepts in force at the time of its exercise. The deductive method and the technique of bibliographical research are used.

KEYWORDS: Privacy. Ontology. Personality. Personal data.

1 Doutorando (bolsista Capes) e mestre em Direito Privado pela Pontifícia Universidade Católica de Minas Gerais (2019) PUC-MG. Bacharel em Direito pelo Centro Universitário de Lavras - Unilavras (2017). Professor substituto de Direito Privado na Universidade Federal de Lavras. Advogado. http://orcid.org/0000-0002-9037-0405. sthefanodivino@ufla.br.

Como citar esse artigo/How to cite this article:

DIVINO, Sthéfano Bruno Santos. Ontologia da Privacidade. Revista Meritum, Belo Horizonte, vol. 15, n. 1, p. 302-321, jan./abr. 2020. DOI: https://doi.org/10.46560/meritum.v15i1.7598. 


\section{INTRODUÇÁO}

A diversidade da sociedade contemporânea demonstra dinâmicas que podem ser identificadas nas Tecnologias da Informação e Comunicação (TIC's) e são capazes de levantar questionamentos sobre garantias adequadas à proteção da privacidade. Pontos de convergência entre forças do mercado e a unidade da pessoa encontram lugar de discussão nas abstrações do ciberespaço.

O questionamento que se coloca como problema de pesquisa é: qual a ontologia da privacidade? Objetiva-se demonstrar a compatibilidade entre as várias experimentações legislativas e doutrinárias em curso, advogando determinadas funções e preceitos à privacidade com a resistência encontrada em aparatos mercadológicos, políticos e burocráticos.

Realiza-se na primeira seção uma breve análise histórica. Analisa-se a compreensão da privacidade do período tribal (entre 200.000 a.C e 6.000 a.C) até sua concepção moderna cunhada em 1890. Frisa-se que tal análise é incompleta. Existe uma limitação de tempo e espaço para tornar efetivo o detalhamento da historicidade desse instituto. Um dos critérios de distinção e de importância a ser evidenciado é a base proprietária da privacidade. Entende-se que, em sua origem, a privacidade se caracterize como propriedade, com suas devidas justificativas evidenciadas ao longo do texto.

Questiona-se na segunda seção a correlação entre proteção da intimidade e da vida privada do sujeito na sociedade da vigilância sob o enfoque de relações e informações socialmente relevantes, sejam elas públicas ou privadas, através de uma nova geração de leis sobre a tutela desse até então reconhecido direito.

Na terceira e última seção, compara-se as características e funções dos direitos da personalidade (sem sentido amplo) para com as características da privacidade. Pretende-se questionar a própria coerência das formulas jurídicas adotadas na doutrina e na legislação de proteção de dados acerca do personalismo da privacidade sob o enfoque histórico até então realizado. Essa, além do mais, é uma reflexão que deve ser realizada para verificar a ontologia da privacidade, que conforme proposto é direcionada a propriedade.

De um lado a defesa desse instituto como direito da personalidade é conhecida e adotada pelo próprio legislador brasileiro nos arts. 11 e 21 do Código Civil de 2002. Lado outro, a proposta evidenciada em aparente compatibilidade com seus aspectos ontológicos direciona a privacidade não apenas como um direito, mas um bem disponível dentro da esfera autônoma existencial de seu titular.

Ao final, pressupõe-se que a caracterização da privacidade como integrante dos direitos da personalidade, bem como sua reprodução nas legislações de proteção de dados e nos marcos legislativos correspondentes aos seus princípios e funções, dificulta sua efetiva proteção em razão da incompatibilidade entre ontologia, dogmática, pragmática e jurídica. Razão essa que autoriza a inserção de uma nova ressignificação desse direito. Para a construção desse raciocínio, utiliza-se o método dedutivo e a técnica de pesquisa bibliográfica. 


\section{2. "PRIVACY MAY BE AN ANOMALY"2}

A privacidade como se apresenta na contemporaneidade é uma concepção relativamente nova, datada de 1890, com o ensaio The Right to Privacy, de Warren e Brandeis (1890). ${ }^{3}$ Esse direcionamento foi moldado pela maioria dos seres humanos que viveram ao longo da história e contribuíram pouco a pouco para a construção e conceituação da privacidade em suas pequenas comunidades.

O que se destaca é que em 3.000 anos de história a privacidade foi delegada para o segundo plano. Seres humanos optam por dinheiro, prestígio ou conveniência quando em conflito com a privacidade, ou o desejo de estar só.

Durante o período tribal (entre 200.000 a.C e 6.000 a.C) o antropologista Jered Diamond destaca que as crianças de caçadores dormiam com seus pais na mesma cama ou na mesma cabana. Inexistia privacidade. Os menores presenciavam relações sexuais de seus genitores. Nas Ilhas Trobriand, Malinowski evidenciou que os pais não tomavam precauções especiais para impedir que seus filhos os observassem fazendo sexo: eles apenas repreendiam a criança e pediam que ela cobrisse a cabeça com um pano. ${ }^{4}$

$\mathrm{Na}$ antiguidade (entre 600 a.C e 400 a.C), os gregos evidenciavam algum gosto pela privacidade. Diferentemente do que ocorria no período tribal, a aplicação de uma evoluída engenharia permitia o povo daquela época a agir a respeito para contemplar seus desejos. Segundo Samantha Burke, a geometria grega possibilitou a criação de moradias com exposição matematicamente mínima à exposição pública enquanto maximizava a entrada de luz disponível no terreno em questão (BURKE, 2000).

Em Roma, os banheiros eram públicos. Ângela (2016, p. 236-240) aponta evidências que pessoas conversavam enquanto se aliviavam em salas abertas com vários banheiros. ${ }^{5}$ Essa argumentação ganha força quando os romanos, mesmo possuindo condições econômicas para construir casas com paredes internas, optavam por exibir suas vidas privadas. Além disso, a maioria dos romanos optavam por viver em apartamentos lotados, com paredes finas o suficiente para ouvir todo barulho. Exibições ostensivas da riqueza naquela época para os demais presentes na sociedade era um símbolo de status (FERESTEIN, 2013).

$\mathrm{Na}$ idade média (400 d.C - 1.200 d.C), santos praticantes do cristianismo inauguraram o conceito moderno de privacidade quando optaram pela reclusão. A popularização da concepção bíblica de que a moralidade não era apenas o resultado de uma ação má, mas a intenção de causar danos, levou seus seguidores mais devotos a se recluírem da sociedade e a se concentrarem obsessivamente no combate de seus demônios interiores, livrando-se das distrações mundanas (FERESTEIN, 2015).

Assim como os peixes morrem se ficarem muito tempo fora da água, os monges que se demoram do lado de fora de suas celas ou passam o tempo

2 Tradução livre: "privacidade pode ser uma anomalia" utilizada por Cerf (2013).

3 Os autores conceituaram privacidade como the right to be alone, ou, em tradução livre, o direito de estar só.

4 Original: "Because hunter-gatherer children sleep with their parents, either in the same bed or in the same hut, there is no privacy. Children see their parents having sex. In the Trobriand Islands, Malinowski was told that parents took no special precautions to prevent their children from watching them having sex: they just scolded the child and told it to cover its head with a mat" (DIAMOND, 2013).

5 "Think of Ancient Rome as a giant campground" (ÂNGELA, 2016, p. 240); "Pense na Roma Antiga como um acampamento gigante" (tradução livre). 
com homens do mundo perdem a intensidade da paz interior. Assim como um peixe indo em direção ao mar, precisamos nos apressar para chegar à nossa cela, com medo de que, se demorarmos para fora, perderemos nossa vigilância interior (KELLER, 2005, p. 51). ${ }^{6}$

Naquela época não havia uma palavra de origem latina ou medieval equivalente à privacidade. Privatio significava tirar (DUBY, 1993). Inclusive, conforme Duby (1993), as plantas das construções dos imóveis daquela época demonstravam que humanos e animais dormiam sob o mesmo teto, no mesmo lugar, pois existia apenas um único cômodo na residência.

No final do período medieval e no início do período renascentista (1300 d.C -1600 d.C), presencia-se a criação dos pilares da privacidade. Para Smith (1975, p. 234), a privacidade é a principal conquista desse período. Logo no início do século XIII os mandamentos da igreja católica postularam a obrigatoriedade das confissões em massa, reformulando o paradigma da moralidade para algo essencialmente privado, deslocado da sociedade, causando uma grande reviravolta em grande parte da Europa.

Posteriormente, o avanço tecnológico foi favorável às diretrizes teológicas presentes naquele momento histórico. Uma nova tecnologia permitiu uma disseminação de ideais de forma silenciosa e muito mais barata: a impressora de Guttenberg. 0 aspecto individualista que já era até então consagrado nos idealizadores e pensadores da época foi reforçado e sobrecarregou a população europeia através da leitura individual. Poetas, artistas, e teólogos tiveram seus ideais de abandono das distrações mundanas fixados com a finalidade de transformação do coração individualista com uma maior relação com Deus. No mais, até meados do século XVIII, embora as leituras públicas estivessem presentes como uma tradição, o estudo silencioso, recluso, foi um luxo de elite por muitos anos (FERESTEIN, 2015).

Outra construção que possibilitou a elaboração do conceito de privacidade foi a invenção dos leitos de dormir. As camas individuais criadas na modernidade eram vistas como um dos itens mais caros da residência. Ela se tornou um local para reuniões sociais, onde os presentes eram convidados a repousar com toda a família e os funcionários daquela residência (FERESTEIN, 2015).

Esse cenário permaneceu até a eclosão e auge da Peste Negra (1343 d.C - 1353 d.C). Até então, a vida europeia sem cuidados higiênicos fez com que doenças infecciosas destruíssem grandes cidades e conglomerados recentemente populados. Essa radical situação obrigou a comunidade a reformular profundamente seus hábitos de saúde e higiene tanto em casa quanto nos hospitais, local esse onde era comum pacientes dormirem próximos uns dos outros (FERESTEIN, 2015).

Embora esse cenário propiciou uma alteração no sentido de privacidade, não quis dizer que situações mais íntimas como o sexo ainda continuavam no sentido privado como entendemos hoje. Era comum, justificado em razões espirituais e logísticas, o testemunho da consumação do casamento. Noivos iam para a cama diante dos olhos da família e dos amigos e,

6 Original: "Just as fish die if they stay too long out of water, so the monks who loiter outside their cells or pass their time with men of the world lose the intensity of inner peace. So, like a fish going towards the sea, we must hurry to reach our cell, for fear that if we delay outside, we will lose our interior watchfulness". Prescrição de St. Abba Antony, pai de todos os monges, (KELLER, 2005, p. 51). 
no dia, seguinte exibiram os lençóis como prova de que o casamento fora consumado (DUBY, 1993).

Neste período não havia uma justificativa tão plausível para demandar e exigir privacidade. Ainda que existissem camas separadas, a maioria das casas possuía apenas um quarto. Conforme Sierlo, arquiteto italiano, a criação de paredes internas não foi destinada à garantia de privacidade, mas para atendimento ao desejo de se aquecer, já que nesse cenário em comento existia apenas uma lareira no centro do cômodo para que as pessoas podiam circulá-la, ver uns aos outros, e se divertirem contando histórias (FERESTEIN, 2015).

A concepção pessoal e jurídica de privacidade começou a se modificar no período da Revolução Industrial (1600 d.C - 1840 d.C). A população começou a exigir o acompanhamento do direito para com as demandas sociais crescentes direcionadas ao secreto. Em 20 de agosto de 1770, Adams, futuro presidente dos Estados Unidos, expressando seu apoio a privacidade, escreveu a seguinte nota: "I am under no moral or other Obligation...to publish to the World how much my Expences or my Incomes amount to yearly" (FERESTEIN, 2015). ${ }^{7}$ 0 desejo da manutenção do privado sob a esfera pública consegue se evidenciar e datar seu crescimento nos séculos posteriores.

Nos anos dourados (1840 d.C - 1950 d.C), a privacidade passa a ser entendida como um "produto distintamente moderno, um dos luxos da civilização" (GODKIN, 1980, p. 12). A concentração de riqueza nas mãos da burguesia serviu de base para as autoridades reconhecer a privacidade como um preceito básico de propriedade da vida humana. ${ }^{8}$ Neste sentido, essa nova necessidade de intimidade fez com que fosse notório o processo no qual intervieram múltiplos fatores, de novas técnicas de construção das habitações à separação entre os locais no qual se vive e o local de trabalho (RODOTÀ, 2008, p. 26). "Aquilo que é privado em contraposição ao que é público deixa de ser identificado por um enfoque político para ganhar força na oposição entre o social e o íntimo" (CACHAPUZ, 2006, p. 68).

Para os pobres, contudo, a vida ainda permanecia pública. Sartre (1998, p. 4) faz um detalhado relato das ruas de Nápoles demonstrando:

The ground floor of every building contains a host of tiny rooms that open directly onto the street and each of these tiny rooms contains a family...they drag tables and chairs out into the street or leave them on the threshold, half outside, half inside...outside is organically linked to inside...yesterday I saw a mother and a father dining outdoors, while their baby slept in a crib next to the parents' bed and an older daughter did her homework at another table by the light of a kerosene lantern...if a woman falls ill and stays in bed all day, it's open knowledge and everyone can see her. ${ }^{9}$

7 "Não possuo nenhuma obrigação moral ou qualquer outra de publicar para o mundo o quantum das minhas despesas e receitas anuais" (tradução livre)

8 Arendt (2010, p. 72 e 87) reforça: "Devemos o pleno desenvolvimento da vida do lar e na família como espaço interior e privado ao extraordinário senso político do povo romano, que, ao contrário dos gregos, jamais sacrificou o privado ao público, mas, ao contrário, compreendeu que esses domínios somente podiam subsistir sob a forma da coexistência

"(...) é que as quatro paredes da propriedade privada de uma pessoa oferecem o único refúgio seguro contra o mundo público comum - não só contra tudo o que nele ocorre, mas também contra a sua própria publicidade, contra o fato de ser visto e ouvido. Uma existência vivida inteiramente em público, na presença de outros, torna-se, como se diz, superficial. Retém a sua visibilidade, mas perde a qualidade resultante de vir à luz a partir de um terreno mais sombrio, que deve permanecer oculto a fim de não perder sua profundidade em um sentido muito real, não subjetivo. 0 único modo eficaz de garantir a escuridão do que deve ser escondido da luz da publicidade é a propriedade privada, um lugar possuído privadamente para se esconder".

9 "O térreo de cada prédio contém uma série de pequenos quartos que abrem diretamente para a rua e cada um desses pequenos quartos contém uma família...eles arrastam mesas e cadeiras para a rua ou as deixam na soleira, metade fora, metade 
Foi em 1890 que o direito à privacidade nasce como produto jurídico de uma reformulação histórica. The Right to Privacy, ensaio seminal de Warren e Brandeis (1890) curiosamente tem como fundamento a proteção da vida íntima e da vida privada frente à invasão da tecnologia na esfera pessoal.

Os preceitos da revolução industrial ainda arraigados em Warren e Brandeis (1890, p. 1) podem ser observados na primeira frase de seu texto: "That the individual shall have full protection in person and in property is a principle as old as the common law [...]". ${ }^{10}$ Não apenas a pessoa, mas também a propriedade entram em pauta na proteção da privacidade. E esse é um ponto interessante, já que quando do debate ou discurso deste atual direito, leva-se apenas em consideração o seu primeiro espectro (pessoa) ${ }^{11}$.

Ocorre que neste momento histórico a privacidade ainda não era caracterizada como norma positivada. Foi apenas em 1903, sob requerimento do presidente norte americano Grover Cleveland, que a câmara legislativa de Nova York estabeleceu uma pena de até U\$1.000 para o uso de imagem não autorizada de alguém para fins comerciais. Isso não se deu de forma automática e em virtude do The Right to Privacy, mas por Cleveland ter se casado com uma esposa considerada linda pelos olhos da mídia. A imagem de Frances Cleveland foi veiculada em inúmeros comerciais televisivos, fazendo com que o presidente pressionasse a câmara legislativa (FERESTEIN, 2015).

A complexidade e a intensidade da vida cotidiana exigiram uma retirada do sujeito do mundo público. Tornou-se essencial para o indivíduo ao menos um momento de solidão e intimidade. Fato esse de difícil concretização com as invenções tecnológicas modernas que sujeitam seus usuários a situações de extrema visibilidade que podem tornar dores e angustias morais muito maiores que aquelas infligidas por danos corpóreos.

Os cartões postais foram um dos primeiros instrumentos a serem utilizados como reserva da vida privada. Relatos de Lane (2009, p. 47) no The Atlantic Monthly explicitam:

There is a lady who conducts her entire correspondence through this channel. She reveals secrets supposed to be the most pro- found, relates misdemeanors and indiscretions with a reckless disregard of the consequences. Her confidence is unbounded in the integrity of postmen and bell-boys, while the latter may be seen any morning, sitting on the doorsteps of apartment houses, making merry over the post-card correspondence. ${ }^{12}$

Outra criação das TIC's bem-sucedida foi o telefone. Embora o valor inicial das linhas individuais era extremamente desproporcional aos padrões atuais, a existência de linhas compartilhadas possibilitava vizinhos e entes mais próximos utilizar e desfrutar dessa função.

dentro...fora está organicamente ligado ao interior...ontem vi uma mãe e um pai jantando ao ar livre, enquanto seu bebê dormia em um berço ao lado da cama dos pais e uma filha mais velha fazia seus deveres de casa em outra mesa à luz de uma lanterna de querosene...se uma mulher adoece e fica na cama o dia todo, é conhecimento aberto e todos podem vê-la" (tradução livre)

10 "Que o indivíduo deve ter plena proteção pessoal e patrimonial é um princípio tão antigo quanto o direito comum" (tradução livre).

11 "O entendimento americano de privacidade decorre especialmente do direito à propriedade, impondo limites ao poder estatal de invadi-la, controlá-la ou de dispô-la. No entanto, a jurisprudência foi se desenvolvendo e hoje apresenta um sentido bem mais complexo que o original" (GARCIA, 2018, p. 6)

12 "Há uma senhora que conduz toda a sua correspondência através deste canal. Ela revela segredos que supostamente são os mais pró-acrescentes, relaciona delitos e indiscrições com um descuido imprudente com as consequências. Sua confiança é ilimitada na integridade dos carteiros e dos sinos, enquanto estes últimos podem ser vistos em qualquer manhã, sentados nas portas dos apartamentos, alegrando-se com a correspondência postal." (tradução livre). 
Party lines could destroy relationships...if you were dating someone on the party line and got a call from another girl, well, the jig was up. Five minutes after you hung up, everybody in the neighborhood - including your girlfriend - knew about the call. In fact, there were times when the girlfriend butted in and chewed both the caller and the callee out. Watch what you say (LANE, 2009, p. 47). ${ }^{13}$

Deste período em diante, ficou evidente a forte desproporção entre os extraordinários efeitos das novas tecnologias e as alterações paradigmáticas marcadas pelo emergir da privacidade como um recurso essencial para a organização do ser. Aspirar tal direito e vê-lo impassível de exercício com tamanha transformação das instituições científicas e jurídicas coloca em xeque a proteção material e imaterial do sujeito.

A pretensão em destaque desta seção se volta para o início da comparação entre os aspectos históricos e jurídicos da privacidade. Esse conjunto de elementos mostra como vai se delineando uma nova fronteira desse aparente direito. Em seu aspecto primário, datado da antiguidade, a privacidade era tida como inexistente. Aparentemente, não existem relatos históricos que colocam a privacidade como direito natural. Uma das redefinições mais recentes da vida íntima é a consagrada pela revolução industrial, que a caracterizava como uma propriedade, um luxo, um bem disponível das classes burguesas.

Pode-se notar com esse breve histórico que durante mais de 3.000 anos a privacidade não era entendida como um direito. Se este é o quadro global a ser observado, a privacidade contemporânea pode ser uma anomalia histórica. E qual a importância disso? Essa constatação tende a favorecer a normatização concreta da privacidade conforme seu aspecto ontológico. A princípio, parece-nos que sua ontologia é voltada para o aspecto cultural e sociopolítico da época em que seu exercício é realizado. Warren e Brandeis apenas a designaram como direito em virtude de suas esferas pessoais serem atingidas. Até então, era tida como um bem, uma propriedade (e isso continua se moldando).

Contemporaneamente vive-se em uma sociedade onde uma vigilância acentuada das TIC's incidem sobre o sujeito, reforçando-se a privacidade como um direito. E com relação à sua natureza? Se se considerarmos a privacidade um fruto cultural, existe compatibilidade com essa proposição e seu exercício? Se o significado é cultural, a indisponibilidade e inalienabilidade a esse instituto ${ }^{14}$ são capazes (ou ao menos eficientes) de remover obstáculos de ordem econômica para garantir uma proteção mais extensa? A próxima seção nos dará elementos para discorrer sobre esses questionamentos.

13 "Linhas de festa poderiam destruir relacionamentos... se você estivesse namorando alguém na linha da festa e recebesse uma ligação de outra garota, bem, a brincadeira já estava no ar. Cinco minutos depois de desligar, todos na vizinhança inclusive sua namorada - sabiam da ligação. Na verdade, houve momentos em que a namorada entrou e mastigou tanto a pessoa que ligou quanto a chamada. Cuidado com o que você diz" (tradução livre).

14 "Art. 11. Com exceção dos casos previstos em lei, os direitos da personalidade são intransmissíveis e irrenunciáveis, não podendo o seu exercício sofrer limitação voluntária" (BRASIL 2002). 


\section{PRIVACIDADE SOB ATAQUE NA SOCIEDADE DA VIGILÂNCIA}

Ao longo dessa linha, por mais que pressupomos a ontologia da privacidade como um produto cultural, ainda não fora apresentado um conceito, pode-se dizer, representativo de sua capacidade de ser tutelada juridicamente. Uma elaboração seminal foi realizada por Alan Westin (2015, p. 12), ao qual "privacy is the claim of individuals, groups, or institutions to determine for themselves when, how, and to what extent information about them is communicated to others". ${ }^{15}$

Alguns autores diferenciam privacidade de intimidade. Para Nery (2015, p. 63),

intimidade é considerada a esfera mais reservada do indivíduo. Lá, suas informações pessoais encontram-se resguardadas para não chegar ao conhecimento alheio, tornando-se um campo inviolável, protegido infra e constitucionalmente, referindo-se, também, à própria imagem diante dos meios de comunicação em massa.

Já a privacidade "situa-se no campo jurídico, são os atos humanos externos à intimidade, reservados pela própria pessoa ou pela sua natureza" (MACEIRA, 2015, p. 64). Dessa forma, "seria a exteriorização de uma parte da intimidade em detrimento de um determinado grupo, local, ou qualquer atividade, seja ela de interação ou não, a título de vontade do indivíduo que decide realizá-la e demonstrar que aquele âmbito constitui sua privacidade" (DIVINO; SIQUEIRA, 2017, p. 227-228).

Para Silva (2008, p. 100), "o conjunto de informação acerca do indivíduo que ele pode decidir manter sob seu exclusivo controle, ou comunicar, decidindo a quem, quando, onde e em que condições, sem a isso poder ser legalmente sujeito" seria o conceito ideal de privacidade.

Ainda que haja essa diferenciação, não se vê utilidade prática em sua defesa. Exatamente o contrário. Essa bipartição tende apenas a dificultar a tutela efetiva da esfera privada dos cidadãos, tendo em vista que são justamente eles a serem os titulares de uma maior quota de poder de controle sobre os aparatos que violam sua autonomia. Dizer se violou a privacidade ou a intimidade, em um aspecto essencialmente subjetivo, abre uma via de mão dupla para a alegação negativa do ofensor sobre o seu papel na esfera particular. ${ }^{16}$

Um dos conceitos mais objetivos encontramos em Rodotà. Para o autor, privacidade é entendida "como o direito de manter o controle sobre as próprias informações" (RODOTÀ, 2008, p. 92). Neste sentido, não existe apenas o controle daquilo que sai, mas também daquilo que entra. E por mais que a formulação de Rodotà esteja ligada à direitos fundamentais e direitos da personalidade, sua posição nos remete sobre uma certa propriedade sob a privacidade, "um novo direito de propriedade sobre os dados pessoais, que se tornaram um bem indispensável e de grande valor da era do direct marketing" (RODOTÀ, 2008, p. 153). Isso é bastante questionável, já que quando abordado sobre comodificação de dados o autor

15 "A privacidade é a reivindicação de indivíduos, grupos ou instituições para determinar por si mesmos quando, como e até que ponto as informações sobre eles são comunicadas a outros" (tradução livre)

16 Cancelier (2017, p. 221), no mesmo sentido: "Para nós, apesar de considerar importante a diferenciação entre os termos privacidade e intimidade, não se enxerga impedimentos no uso da expressão direito à privacidade pra tratar do direito à intimidade, afinal este está inserido naquele". 
basicamente denega qualquer tipo de possibilidade por se tratar de fruto da esfera subjetiva da pessoa.

A proposta de considerar os dados ${ }^{17}$ como "propriedade" do interessado revela uma tutela insuficiente justamente sob o perfil do direito fundamental à privacidade, porque a possibilidade de negociar uma contrapartida econômica se apresenta como único instrumento capaz de atribuir ao interessado um real poder de controle sobre os próprios dados que, de outra forma, poderiam ser coletados sem o seu consentimento ou até mesmo sem o seu conhecimento.

Aqui encontramos talvez o paradoxo do presente escrito. Como efetivar a proteção da privacidade sem considerá-la algo disponível, maleável, na esfera de seu titular? Estudos demonstram a possibilidade do aceite do usuário na venda de seus dados se concedida uma contraprestação. Um desses estudos foi realizado na Universidade da Pensilvânia, o que resultou no seguinte questionamento: "please think about the supermarket you go to most often. Let's say this supermarket says it will give you discounts in exchange for its collecting information about all your grocery purchases. Would you accept the offer or not?" (TUROW, 2015 , p. 12). ${ }^{18}$ Curiosamente um percentual de $43 \%$ das pessoas entrevistadas concordaram com a prática ${ }^{19}$.

A assunção de funcionalidades múltiplas trazidas pela tecnologia insere-se o desenrolar dos vários momentos de uma jornada na vida de uma pessoa. Sua dimensão não apenas diacrônica, mas também sincronizada com a identidade do sujeito derruba barreiras e assume uma posição interativa contínua entre humanos e máquinas. A cada momento, modifica-se radicalmente o contexto em que a pessoa constrói seu caminho e sua referência significativa subjetiva e objetiva. Em uma dimensão jurídica, isso não é diferente (SANTOS DIVINO, 2019).

Especialmente na seara do consumo, a discussão sobre a proteção do consumidor no comércio eletrônico não é relativamente nova, mas também não o é antiga. A referência legislativa no direito estrangeiro responsável pelo reconhecimento dos contratos eletrônicos como negócio jurídico deu-se na Lei Modelo da Uncitral sobre o Comércio Eletrônico, de 1997 , em seus arts. $5^{\circ}$ e $11^{20}$. No Brasil, a discussão toma pauta no início dos anos 2000 ,

17 Um questionamento pode surgir acerca da diferença entre direito de privacidade e proteção de dados. Em princípio, a divergência existente entre eles aparentemente é terminológica. Porém, tenta-se delimitar o escopo de abrangência de ambos. Enquanto o direito de privacidade constitui-se como autônomo instituto da personalidade de seu titular, possibilitando que ele controle o que entra e o que sai de sua esfera privada através de sua autodeterminação informativa, a proteção de dados pode ser considerada como espécie do gênero privacidade. Pode-se dizer que são duas faces da mesma moeda. 0 exercício da proteção de dados encontra fundamento não apenas na autodeterminação informativa, mas também na privacidade, pois àquela está inclusa nessa. Verifica-se que, apesar da proteção de dados restringir-se apenas a um dos aspectos da privacidade, se visualizada como um todo crê-se que são complementares. Sob essa ótica, não parece lógico estipular uma dicotomia e estratificar, de um lado, o direito de privacidade, e de outro, a proteção de dados. Ontologicamente são unificados. Mas, a fim de delimitar e atender aspectos didáticos, a proteção de dados consagra-se como espécie da privacidade para atenção e delimitação de atos informacionais que são retirados da esfera particular de seu titular, enquanto o direito a privacidade aborda algo mais amplo, não se restringindo apenas a essas informações coletadas e processadas em âmbito virtual.

18 "Por favor, pense no supermercado onde você vai com mais frequência. Digamos que este supermercado diz que lhe dará descontos em troca da coleta de informações sobre todas as suas compras de mercearia. Você aceitaria ou não a oferta" (tradução livre).

19 Denominada câmbio de troca (trade-off). Mais em (IAB, 2010).

20 "Article 5. Legal recognition of data messages. Information shall not be denied legal effect, validity or enforceability solely on the grounds that it is in the form of a data message Article 11. Formation and validity of contracts (1) In the context of contract formation, unless otherwise agreed by the parties, an offer and the acceptance of an offer may be expressed by means of data messages. Where a data message is used in the formation of a contract, that contract shall not be denied validity or enforceability on the sole ground that a data message was used for that purpose" (UNITED NATIONS, 1999, p. 5).

"Artigo $5^{\circ}$. Reconhecimento legal das mensagens de dados. Não serão negados os efeitos legais, a validade ou a aplicabilidade das informações somente pelo fato de estarem na forma de uma mensagem de dados Artigo 11. Formação e validade 
principalmente com Marques (2004). Já naquela época, a autora visualizava a possibilidade de existência e ampliação de um espaço trazido pela internet expresso nas redes eletrônicas e de comunicação em massa para conquistar a confiança e elaborar mecanismos de praticidade aos consumidores, "bem como reconstruir a dogmática desconstruída" contratual (SANTOS DIVINO, 2019).

As reflexões em torno dessa temática aparentemente são amplas. 0 caráter inovador da tecnologia evidencia mudanças nas relações entre o cidadão e o mercado de consumo. Essa descrição comum à característica de uma sociedade sucumbida ao critério informacional denota um crescimento assombroso da participação desses sujeitos no mundo virtual. Os contratos eletrônicos operam a experiência consumerista na sociedade em rede. Para verificar qual o papel e qual a posição do consumidor nas relações contratuais eletrônicas, denominadas e-commerce, seria um engano analisa-las exclusivamente sob o aspecto teórico. Algumas considerações práticas devem ser apontadas como caráter geral para subsidiar a presente argumentação.

Considerando as experiências concretas e os experimentos do e-commerce, identificamos a influência de uma pluralidade de instrumentos utilizados para efetiva satisfação do consumidor. A organização das estruturas privadas na formação de redes contratuais possibilita o acesso a informações e o fornecimento de serviços on-line através de ferramentas e procedimentos estruturados e diferenciados em novas perspectivas.

A relevância que assumiu o comércio eletrônico e, de forma genérica, a dimensão econômica, induz a transformação da internet em um local asséptico, onde o próprio consumidor, seja adulto ou criança, pode entrar como se fosse um imenso shopping center, um centro comercial sem fronteiras, sem correr o risco de ter sua atenção desviada de qualquer coisa que não seja a atividade consumerista (RODOTÀ, 2008, p. 179). Estamos, contudo, diante de uma situação complexa: a partir do momento em que a utilização comercial transcende todas as outras modalidades de utilização contratual, em virtude de sua praticidade e comodidade, o formato da internet e sua própria natureza transformam-se profundamente e emergem novas demandas e propostas para regular esse cenário. Ao fornecedor de produtos ou serviços no e-commerce é imprescindível o aceite do consumidor para coleta e tratamento de dados destinadas à finalização daquela relação consumerista. Caso o consumidor negue, não poderá finalizá-la (SANTOS DIVINO, 2019).

Existe, nesse mesmo sentido, a concepção de falsa gratuidade da prestação dos serviços. O ponto fundamental diz respeito, seguramente, à possibilidade econômica sobre a privacidade dos consumidores. Redes sociais são exemplos que utilizam contratos eletrônicos não remunerados de forma direta para o fornecimento de produtos e serviços em rede. Ocorre que existe uma certa onerosidade do acesso às redes sociais, pois a privacidade e os dados pessoais possuem valor econômico para obtenção de vantagens patrimoniais.

A propósito, um estudo de 2012 sobre o tema revelou que, se as redes sociais fossem sustentadas por usuários, em vez de anunciantes, a mais cara seria o Facebook, custando 5.04 dólares por ano ou 42 centavos de dólar por mês.

dos contratos (1) No contexto da formação do contrato, salvo acordo em contrário entre as partes, uma oferta e a aceitação de uma oferta podem ser expressas por meio de mensagens de dados. Quando uma mensagem de dados for utilizada na formação de um contrato, não será negada a validade ou aplicabilidade desse contrato pelo simples motivo de uma mensagem de dados ter sido utilizada para esse fim" (tradução livre). 
O Twitter custaria 2.29 dólares por ano; o Linkedin, 1,50 dólares por ano; e, o YouTube, 1,17 dólares (CORDEIRO; KONDER, 2019, p. 197).

Quando da utilização dos serviços do Facebook (2020), por exemplo, o usuário titular em causa fornece dados sobre compartilhamento de conteúdo; envio de mensagens; comunicação com outros usuários, podendo incluir informações presentes no conteúdo ou a respeito dele. Depois da coleta dessas informações, que já foram processadas por meio de dados inicialmente captados, o Facebook poderá utilizá-las para, entre outras finalidades: enviar comunicações de marketing; melhorar os sistemas de publicidade e medição, podendo mostrar anúncios que a empresa considere relevantes para a pessoa em causa, tanto dentro quanto fora dos serviços oferecidos, além de medir a eficácia e o alcance dos anúncios e serviços contendo dados de quantas pessoas visualizaram os anúncios ou instalaram um aplicativo depois de verem um anúncio; ou proporcionar informações demográficas para ajudar seus parceiros a entenderem seu público ou os clientes.

Não há como um serviço que seja realmente gratuito, ainda que de abrangência mundial e com inúmeros partícipes, atingir essa correspondência monetária. As técnicas combinadas dos fatores de tecnologia de informação e da coleta e do tratamento de dados pessoais possibilitam às mídias interativas obterem renda com publicidade. A disciplina trazida nos termos de serviços e na política de privacidade não é meramente protetiva. 0 cerne das possibilidades oferecidas e as distinções incrementadas nesses instrumentos contratuais extraem indicações em duas direções (DIVINO, 2018).

A defesa da privacidade requer, portanto, uma expansão da perspectiva institucional ontológica, superando sua concepção puramente subjetivista, como um direito aparentemente indisponível e indelegável, como também sua concepção puramente proprietária. Deve existir e comutar um conjunto das disciplinas de acordo com as funções para as quais são destinadas a tutela da intimidade. Existem, contudo, desafios a serem enfrentados contra a concepção jurídica contemporânea de privacidade.

\section{ONTOLOGIA DA PRIVACIDADE: ENTRE DIREITO DA PERSONALIDADE E BEM DISPONÍVEL}

Quando existe a alternação da sociedade aos indivíduos, do coletivo para o singular, as polaridades se acentuam e se tornam mais perspectiveis aos olhos de participantes assíduos. Para delimitar o esquema da nova realidade proveniente de experiências e analises passadas, faz-se indispensável a atribuição conceitual para percepção do contexto em que se constituem as relações entre as pessoas, entre os indivíduos e as organizações sociais. Partindo dessa constatação, três conceitos são essenciais: personalidade, direito da personalidade e pessoa.

Personalidade refere-se à "uma suscetibilidade de ser titular de direitos e obrigações jurídicas" (DE CUPIS, 2008, p. 19). Os direitos a ela atribuídos são "faculdades jurídicas cujo objeto são os diversos aspectos da própria pessoa do sujeito, bem assim seus prolongamentos e projeções" (FRANÇA, 1983, p. 37). A pessoa, por sua vez, aparentemente seria o ente 
dotado de liberdade da vontade, a vontade de sentido e o sentido da vida, capaz de exercer o que lhe couber e o que lhe for atribuído (FRANKL, 1994, p. 16).

Observa-se que a diferenciação entre as proposições acima é visível. Opta-se pela utilização apenas do termo direito da personalidade para evitar ambiguidades, permitindo ao leitor identificar o pretendido no presente trabalho. Os demais termos não serão trabalhados por não haver uma intrínseca relação com essa seção.

Ao analisar o conceito de direito da personalidade, percebe-se a importância de inserir no seu escopo determinadas funções. Se estamos na ordem da pessoalidade e da subjetividade, tais funções e limitações somente podem ser consideradas legítimas nos casos de compatibilidade com a autonomia privada do seu titular, igualmente fundamentada no livre exercício da vida.

Esta particular intersecção evidencia que as características - e também as funções dos direitos da personalidade são resultantes de uma descrição exemplificativa. Não se a taxa em virtude de seu incomensurável alcance e origem. Para Schreiber (2014, p. 228),

Suas funções jurídicas são outras, como, por exemplo: (I) evidenciar as diferentes ameaças que cada um desses atributos pode sofrer, facilitando a prevenção de danos (função preventiva); (II) permitir, por meio do desenvolvimento de instrumentos específicos, a mais plena reparação das lesões que venham a atingi-los (função reparatória); (III) auxiliar a formulação de parâmetros próprios para a ponderação nas hipóteses de colisão entre os próprios direitos da personalidade ou entre eles e outros direitos fundamentais (função pacificadora); e (IV) estimular o desenvolvimento desses atributos por meio de políticas públicas e iniciativas sociais adequadas (função promocional).

A dissertação através dessas funções leva tanto o legislador ${ }^{21}$ quanto parte dos juristas atribuição de características condizentes com a condição humana de tais direitos. Conforme $\operatorname{Bittar}(2015$, p. 43),

Com efeito, esses direitos são dotados de caracteres especiais, para uma proteção eficaz à pessoa humana, em função de possuírem, como objeto, os bens mais elevados da pessoa humana. Por isso é que o ordenamento jurídico não pode consentir que deles se despoje o titular, emprestando-Ihes caráter essencial. Daí, são, de início, direitos intransmissíveis e indispensáveis, restringindo-se à pessoa do titular e manifestando-se desde o nascimento (Código Civil de 2002, art. $2^{\circ}$ ).

Em suas características gerais e principiológicas são direitos inatos (originários), absolutos, extrapatrimoniais, intransmissíveis, imprescritíveis, impenhoráveis, vitalícios, necessários e oponíveis erga omnes, como tem assentado a melhor doutrina, como leciona, aliás, 0 art. 11 do novo Código. ${ }^{22}$

21 "Art. 11. Com exceção dos casos previstos em lei, os direitos da personalidade são intransmissíveis e irrenunciáveis, não podendo o seu exercício sofrer limitação voluntária. Art. 20. Salvo se autorizadas, ou se necessárias à administração da justiça ou à manutenção da ordem pública, a divulgação de escritos, a transmissão da palavra, ou a publicação, a exposição ou a utilização da imagem de uma pessoa poderão ser proibidas, a seu requerimento e sem prejuízo da indenização que couber, se lhe atingirem a honra, a boa fama ou a respeitabilidade, ou se se destinarem a fins comerciais" (BRASIL, 2020). 
O reconhecimento da privacidade como direito da personalidade é considerado de grande vulto na doutrina brasileira. Além de Schreiber (2014) e Bittar (2015), uma breve pesquisa demonstra a articulação entre a premissa postulada e sua relação empírica. ${ }^{23}$

Entende-se que o sentido da privacidade na sociedade da vigilância deve transcender seu aspecto dogmático, relacionando-se com a concretização dos valores da humanidade em cada sociedade e cultura vigente à época de seu exercício (NASCIMENTO, 2017). A violação deste direito na rede virtual propôs a criação de novos mecanismos legislativos para tutela, reparação e compensação dos danos advindos dessa conduta. Um fio condutor requereu a liberação de fatores externos na formação da privacidade e da personalidade do indivíduo. Neste cenário as legislações de proteção de dados surgiram com a função de marcar o fato de pertencer a um grupo privilegiado de normas destinadas à regulamentação extensa da subjetividade do titular desse direito.

Essa realidade é mais complexa e acomete progressivamente toda a tutela subjetiva. Explica-se. Tanto no regulamento 2016/679 da União Europeia quanto na Lei 13.709/2019, ambas responsáveis pela instauração de um Regime Geral de Proteção de Dados, a tônica do consentimento é o cerne da discussão.

Em primeiro lugar deve-se delimitar o aspecto conceitual desse termo, mas tal tarefa não é fácil. Parte-se do pressuposto de que um sujeito de direito tenha autonomia para decidir e escolher sobre os aspectos de sua vida. 0 exercício desse discernimento como ferramenta singular desenvolve a autodeterminação como capacidade de prática ou não de um determinado ato que lhe é posto. Especificamente no campo jurídico, a aplicação do consentimento se dá como elemento constitutivo da esfera negocial. A externalização psíquica desse consentimento, dessa vontade, desse desejo, dessa crença de realizar algo e desse fenômeno intencional é o que se pretende para constituição de um contrato. Um sujeito $X$ somente vende um bem móvel ou imóvel pois tem intenção de assim fazê-lo. A partir de critérios racionais acrescidos de discernimento, o sujeito desenvolve uma capacidade mental de exercício para escolher aquilo que pretende para sua vida. Esse aspecto é estendido, inclusive, a direitos considerados personalíssimos, como a efetivação econômica do direito de imagem. Um sujeito de renome que pretende, deseja, intenciona o exercício econômico de sua imagem, quer que assim seja mediante a externalização psicológica de sua vontade no aspecto prático que poderá ou não ficar registrado em um instrumento contratual. Portanto, o consentimento é considerado chave-mestra e elemento indispensável a constituição de um negócio jurídico. Ninguém, a princípio, pode ser parte em um contrato que não deseja. 0 conteúdo das cláusulas contratuais deve ser compatível com as diretrizes psicológicas objetivadas pelo contratante, sob pena de violação de sua autonomia e da boa-fé objetiva. Assim, o consentimento adquire um importante papel para o exercício do titular como pessoa. Sua realização como bem maior está na satisfação e na concretização do bem objetivado pelo seu consentimento, abstraído de seu discernimento e de seus critérios racionais. A grosso modo, portanto, o consentimento é do que a externalização da intencionalidade do indivíduo através de atos de fala para o exercício e prática de um ato que ele objetiva. Dessa forma, o consentimento destinado ao tratamento de dados somente será concedido se o titular compreender e intencionar com tal atitude (SANTOS DIVINO, 2019). 
0 art. $7^{\circ}$ da LGPD (BRASIL, 2018) brasileira afirma algumas hipóteses alternativas em que seria legítimo o tratamento de dados. Entende-se que neste momento que como o legislador utilizou a conjunção disjuntiva ou no final do inciso IX, caso configurada qualquer das hipóteses presentes nos demais incisos seria autorizado o tratamento de dados, independentemente de ter ou não consentimento. Veja-se: em uma leitura hermenêutica, caso o legislador decidisse pela aplicação integral do consentimento nas demais hipóteses prescritas no normativo em questão, teria criado alíneas no inciso I, ao invés de confeccionar outros incisos (ou melhor, incluído tal requisito no caput do artigo). Além disso, utiliza-se a conjunção disjuntiva ou, ao tempo em que poderia ter limitado as hipóteses à confecção da primeira. Por essa razão, ainda que não haja consentimento do titular, caso fique configurada qualquer das hipóteses presentes nos incisos II ao X, será legítimo o tratamento de dados, desde que respeitados os demais princípios legislativos (SANTOS DIVINO, 2019).

Em regra, a legislação assume uma postura protetiva e elenca duas situações nas quais é possível realizar o tratamento desses dados. A primeira exige, de forma específica e destacada, o consentimento do titular dos dados para realizar o tratamento de dados, desde que delimitada a finalidade (art. 11, caput, I, da LGPD). A segunda (art. 11, II, a-g, da LGPD) dispensa o consentimento, mas somente se dará em hipóteses excepcionais. Todas essas situações são enumerações taxativa e não admitem interpretação ampliativa. Qualquer outra situação que não esteja aqui elencada ou que o consentimento do titular esteja ausente ou inverificável impedirá a ação do agente de tratamento.

É certo que existem estratégias que se contrapõem a tais lógicas e estruturas organizacionais legais, tal como os moldes contratuais eletrônicos contemporâneos. Estes, considerados clickwrap ${ }^{24}$ ou point-and-click dificultam uma análise mais precisa para verificação dos requisitos acima designados. Porém, a força das novas tecnologias e sua sinergia com as legislações devem assumir uma postura para facilitar esse fato, tal como a criação de modelos contratuais específicos destinados à cessão facultativa dos dados pessoais pelo titular ao utilizar determinado serviço. 0 que se deve ter em mente, em primeiro lugar, é que o desígnio do consentimento como lócus do tratamento de dados delineia algumas tendên-

24 "Como modalidade particular de contratos de adesão, no campo da contratação eletrônica, impende destacar as chamadas licenças clickwrap ("clickwrap agreements" ou "point-and-click agreements"), usualmente submetidas à concordância do usuário do produto ou serviço, contendo cláusulas acerca da sua prestação, sendo assim denominadas, pois sua validade se baseia no ato de apertar o botão de aceitação (frequentemente por intermédio do mouse), guardando grande similitude para com as licenças shrinkwrap utilizadas na comercialização de software, nas quais a aceitação ocorre no ato da abertura da embalagem que contém os suportes físicos onde se encontra o programa" (MARTINS, 2016, p. 131).

No mais, o termo "clickwrap" advém do termo "shrinkwrap", utilizado para designar compras de software efetuadas em grandes demandas. Sua intrínseca relação com a propriedade intelectual adquire grande relevância em 1996, com o julgamento ProCD, Inc. v. Zeidenberg. "In ProCD, a manufacturer of computer software (ProCD), compiled information from over 3,000 directories into a telephone book database containing approximately 95 million telephone listings (at considerable expense) and developed a search engine to be used in conjunction with the database. In order to effectively market the software, ProCD licensed the database at different prices-higher prices for commercial users and lower prices for private users. A problem arose, however, when Zeidenberg bought a private user package, but ignored the license, extracted the listings, and made the database commercially available over the Internet through his own proprietary search engine. ProCD sued Zeidenberg, claiming Copyright infringement and breach of the shrinkwrap license agreement" (COVOTTA; SERGEEFF, 1998, p. 35-54). (1998). A importância da presente jurisprudência é a consideração da possibilidade da força vinculante das licenças clickwrap e shrinkwrap. Os termos ali descritos, conforme a decisão da corte norte americana, possuem caráter contratual e são equiparados ao princípio do pacta sunt servanda. Ou seja, aquilo que foi pactuado, deverá ser cumprido. Essa posição traz sérias considerações. Primeiramente deve-se compreender que não há qualquer redução teórica do consentimento a esse tipo de modalidade contratual. Enquanto o consentimento é fator de intencionalidade, algo de caráter essencialmente subjetivo que está ligado a autonomia e autodeterminação do seu titular, tanto o clickwrap quanto o shrinkwrap são modalidades contratuais eletrônicas em que o titular a utilizará como eventual forma de expressão de seu consentimento. Enquanto um tem uma acepção subjetiva, o outro adquire uma noção jurídica e formal. 
cias, principalmente principiológicas, das quais não foram esquecidas pela lei. Pelo contrário, foram elencadas em um rol específico.

O problema é o que fazer para que esse consentimento seja coletado. Os modelos contratuais eletrônicos atuais não favorecem essa prática. A simples atitude de clicar em uma caixa de diálogo e aceitar os Termos de Prestação de Serviços e a Política de Privacidade evidentemente não é algo que possa afirmar pela concessão do consentimento. Pois, a leitura desse tipo contratual, por conter inúmeros traços técnicos, prejudica o entendimento de pessoas leigas. Isso quando fazem a leitura. Pois, em maior parte do tempo, conforme os primeiros autores, $74 \%$ das pessoas ignoram tais termos e políticas (OBAR; OELDORF-HIRSCH, 2018).

Com essas ponderações, retorna-se às dinâmicas ontológicas e próprias da vida privada. A incompatibilidade tecnológica para com as legislações de proteção de dados e também para com o desenvolvimento social sob intensa vigilância impossibilita a efetiva proteção desse direito nos termos pretendidos pelo seu titular. Privacidade e dados pessoais, hoje, possuem um alto valor econômico capaz de limitar ou excluir outras formas de tutela jurídica sob a dimensão virtual.

Essa realidade mais complexa acomete progressivamente toda a organização social. É preciso considera-la ao traçar os novos parâmetros para os direitos e organização social, para interferir diretamente nessa dimensão e garantir a liberdade do sujeito. Uma ressignificação da privacidade torna-se necessária para favorecimento do seu desenvolvimento como algo controlável na esfera íntima de seu titular.

Incursos iniciais já destacam dimensões reformuladas para a reinterpretação deste direito. A primeira delas denominada decisional. "[...] é o tipo de proteção que se dá ao modo de vida do indivíduo, incluindo aí as suas escolhas, seus gostos, seus projetos, suas características" (PEIXOTO, EHRHARDT JR, 2018, p. 48). A segunda, informacional, derivada de Solove (2008), entende que a privacidade deve ser vista sob uma ótica contextualizada em seus particulares, e não apenas como algo abstrato". Por fim, a terceira dimensão, denominada espacial, "[...] volta-se àquela que é a mais tradicional dimensão da privacidade de todas, aquela dimensão original, de onde todo assunto relativo à privacidade se desenvolveu. É a privacidade do lar, a privacidade de um cômodo da casa, de determinado lugar físico" (PEIXOTO, EHRHARDT JR, 2018, p. 54).

Embora a descrição da última decisão seja questionável, tendo em vista que o desenvolvimento da privacidade entre paredes foi se dar apenas pós-revolução industrial, a ideia central é de uma proposta de reformulação da privacidade para que atenda aos interesses legítimos contemporâneos, ou seja, sua proteção.

O que se propõe, neste momento, é colocar o problema da defesa da privacidade em uma dimensão na qual são justamente as tecnologias da informação e da comunicação possibilitam sua defesa e seu exercício. Leva-se em consideração sua ontologia. Dizemos inicialmente que por se tratar de um fruto cultural, o aspecto privatístico é moldado pelos costumes sociais. Na sociedade da vigilância contemporânea, privacidade nada mais é do que um recurso econômico utilizado para o desenvolvimento de grandes empresas. E como o sujeito titular se posiciona frente a isso? 
Apesar de o regulamento geral de dados ter sido promulgado recentemente, na União Europeia havia a Diretiva 95/46/CE do Parlamento Europeu e do Conselho, de 24 de outubro de 1995, relativa à proteção das pessoas singulares no que diz respeito ao tratamento de dados pessoais e à livre circulação desses dados. Isso, contudo, não impediu o emblemático Caso da Cambridge Analytica (DAVIES, 2015), apesar do Regulamento 679/2016 ter bastante conteúdo textual em comum com sua norma revogada.

O que se espera deduzir deste raciocínio é que o mercado e a sociedade não serão obstados pela imposição do consentimento necessário a coleta e tratamento de dados pessoais, bem como pela impossibilidade de entrincheirar uma espécie de perfil social das tecnologias, no sentido da criação necessária de riscos para a esfera privada. Isso quer dizer que programas serão utilizados em rede para a contínua prática contemporânea da violação da privacidade. Em primeiro lugar pois as legislações encontram, em regra, limites territoriais para sua efetiva aplicação. Já a internet é algo transcendental de fronteiras soberanas. Lado outro, é basicamente inviável, sob a ótica econômica, coletar todo e qualquer tipo de consentimento em rede para que haja efetiva concretização do contrato que está sendo elaborado.

Isso, contudo, não afeta apenas as relações virtuais, embora direcione o foco especialmente a elas. Postula-se que as características de indisponibilidade, inacessibilidade e inalienabilidade cessem e possibilitem ao titular da privacidade auferir ganhos e lucros proporcionais aos que a empresa responsável pela violação de sua privacidade (lato sensu - abrangendo também coleta e tratamento de dados). Vê-se que, conforme a ontologia da privacidade, direcionada a um elemento moldado culturalmente, o desenvolvimento jurídico ignorou o desenvolvimento histórico e partiu das premissas de Warren e Brandeis como se fosse um resultado suprassumo e imediato da sociedade.

A visão deste direito como um bem parece ser mais viável que apenas um direito da personalidade indelegável, incessível, indisponível e inalienável. O suporte da autonomia existencial do ser permite que ele concentre em seus atos de autonomia privada o que se pretende entrar e sair de sua esfera íntima. Nesse mesmo sentido, as disposições elementares que não contrariam sua significação humana são passíveis de efetivação econômica. 0 que é privado interessa apenas ao seu titular. Se se deseja tornar público, não cabe ao poder judiciário tomar atitudes para vedar tal conduta. No mais, se se pretende auferir ganhos econômicos com tal prática, desde que conforme dito não contrarie ou modifique sua posição ou redução da condição humana a um nível extremamente decadente, impassível de exercício da própria dignidade, deve-se autorizar e regulamentar apenas os resultados. A vedação desse tipo de objeto tende apenas a dificultar e transformar em hipocrisia algo que permitiria uma ligação social mais equilibrada entre sujeito e indivíduo.

Assim, a imposição a todos das características dos direitos da personalidade para a privacidade parece ser desvinculada do seu contexto histórico. Deve-se analisar sua feição como propriedade e, em primeiro lugar, permitir a livre disposição ao seu titular. Não seria mais justo que o particular participasse do aspecto econômico de algo que já é exclusivamente seu. Em épocas difíceis, malgrado os inegáveis atrasos legislativos e o planejamento dos sistemas jurídicos para promover tal tutela. 


\section{CONCLUSÃO}

Colocando em discussão o atual sistema de direito da personalidade que abrange a privacidade, fez-se necessário refletir sobre o papel que ambos se revelam perante os sujeitos institucionais. Os aspectos mercadológicos e políticos utilizam desse circuito social modificado para auferir renda e estabelecer regras particulares entre os primeiros e os titulares do direito à privacidade.

Nessa concepção surgem as normas e legislações direcionadas à proteção da vida íntima. De fato, ainda que códigos deontológicos e de boa conduta direcionem às categorias interessadas, neste caso os titulares dos direitos, as regras estabelecidas tendem a disciplinar uma relação aparentemente utópica. Na fase de elaboração contratual, conforme visto, a referência sobre a coleta do consentimento, se elaborada nos moldes positivados na norma, tende a impugnar e obstar as contratações eletrônicas. E, de um certo ponto de vista, existem limites territoriais que devem ser observados para a correta aplicação jurisdicional de determinado país.

Nesta perspectiva, a primeira seção foi responsável por demonstrar a ontologia da privacidade. Em seu aspecto histórico, a privacidade era caracterizada como propriedade. Sua essência, assim então direcionada, deve ser utilizada como molde para as futuras construções jurídicas e socioeconômicas, fato esse não detectável.

Na segunda seção ficou evidenciado, sob uma análise empírica, que os preceitos legislativos, normativos e jurídicos atualmente advogados pela comunidade legal aparentemente são incompatíveis com as características personalíssimas atribuídas a esse direito. Conforme pesquisa levantada e apontada por Turow, Henessy e Draper, as pessoas comutariam dados pessoais em descontos em supermercados. Isso significa que a tendência para alienação desse bem, ou ao menos a cessão temporária realizada sob o enfoque econômico, já é prática e aceito perante a comunidade titular desse direito.

O que se pretendeu com a constatação na segunda seção foi a demonstração da existência de uma reformulação ou ressignificação da privacidade no contexto informacional. Aparentemente, advoga-la como direito da personalidade apenas dificultaria o seu pleno exercício e tutela. De um lado impede que seus titulares possam livre cedê-la ou dispô-la no mercado de consumo, caso assim queiram. De outro, as legislações de proteção de dados aparentemente se tornam uma ineficaz utopia em virtude de se seguidos os preceitos ali elencados toda a contratação econômica mercadológica tende a parar para a coleta do consentimento do sujeito.

Dessa forma, uma solução para esse problema, em contraste com uma nova tendência protetiva, pleiteia-se que a privacidade seja vista não apenas como um direito da personalidade, mas como um bem disponível componente da esfera autônoma existencial da pessoa. o que é privado só interessa para aquele que detém o sigilo. Caso seu titular queira disponibilizá-lo nada pode fazer o Estado para obstar tal conduta. E se isso pode ser realizado de forma gratuita, por que não de forma onerosa, a fim de possibilitar ganhos proporcionais ou fracionais aos titulares que assim o exercita? É necessário ter isso em conta.

Considerando as atuais experiências em um quadro de equilíbrio democrático, conhecemos o papel central da internet. Seu crescimento é significativo para todas as áreas da 
ciência, incluindo o direito. Seria um engano extrair desse cenário a sobrevivência de um movimento que não pode fundar-se somente nas suas raízes jurídicas. As relações eletrônicas deram origem a um paradigma que, até o momento, mesmo na presença de inovações revolucionárias, verifica-se uma complexa reorganização jurídica e social. Neste sentido, estamos caminhando a poucos passos, mas para a direção errada.

\section{REFERÊNCIAS}

ÂNGELA, Alberto. A Day in the Life of Ancient Rome. New York: Europa Editions, 2016, p. 236-240.

ARENDT, Hannah. A condição humana. 11. ed. Rio de Janeiro: Forense Universitária, 2010.

BRASIL. Lei n 10.106 de 10 de janeiro de 2002. Institui o Código Civil. In: Diário Oficial da República Federativa do Brasil, Brasília, DF, 10 jan. 2002. Disponível em: http://www.planalto.gov.br/ccivil_03/leis/2002/I10406.htm. Acesso em: 06 jan. 2020.

BITTAR, Carlos Alberto. Os direitos da personalidade. 8. ed. São Paulo: Saraiva, 2015.

BURKE, Samantha. Delos: Investigating the notion of privacy within the ancient Greek house. Thesis submitted for the degree of Doctor of Philosophy at the University of Leicester. 2000. Disponível em: https://leicester.figshare. com/articles/Delos_Investigating_the_notion_of_privacy_within_the_ancient_Greek_house/10097996. Acesso em: 04 jan. 2020.

CACHAPUZ, Maria Cláudia. Intimidade e vida privada no novo código civil brasileiro: uma leitura orientada no discurso jurídico. Porto Alegre: Sérgio Antônio Fabris, 2006.

CANCELIER, Mikhail Vieira de Lorenzi. O Direito à Privacidade hoje: perspectiva histórica e o cenário brasileiro. Sequência (Florianópolis) [online]. 2017, n.76, pp.213-239. ISSN 0101-9562. http://dx.doi.org/10.5007/2177$-7055.2017 \mathrm{v} 38 \mathrm{n} 76 \mathrm{p} 213$.

CERF, Vint, Internet Innovator Vinton G. Cerf to Keynote FTC's Internet of Things Workshop Nov. 19. Federal Trade Commission: protecting america's consumers. out. 2013. Disponível em: https://www.ftc.gov/news-events/ press-releases/2013/10/internet-innovator-vinton-g-cerf-keynote-ftcs-internet-things. Acesso em: 04 jan. 2020.

CORDEIRO, A. G.; KONDER, C. N. Onerosidade do acesso às redes sociais. Revista De Direito Do Consumidor, v. 121, p. $185-212,2019$

COVOTTA B.; SERGEEFF P. (1998) ProCD, Inc. v. Zeidenberg, 13 Berkeley Tech. L.J. (35), 35-54. https://doi. org/10.15779/Z38408Q.

DAVIES, Harry. Ted Crus using firm that harvested data on millions of unwitting Facebook users. The Guardian. Disponível em: <https://www.theguardian.com/us-news/2015/dec/11/senator-tedcruz- president-campaign-facebook-user-data>. Acesso em 07 jan. 2020.

DE CUPIS, Adriano. Os Direitos da Personalidade. São Paulo: Quorum, 2008.

DIAMOND, Jered. The World Until Yesterday: What Can We Learn from Traditional Societies? London: Penguin Books, 2013.

DIVINO, Sthéfano Bruno Santos. A aplicabilidade do Código de Defesa do Consumidor nos contratos eletrônicos de tecnologias interativas: o tratamento de dados como modelo de remuneração. Revista De Direito Do Consumidor, v. 118, p. 221-246, 2018.

DIVINO, Sthéfano Bruno Santos; SIQUEIRA, Lucas André Viegas Carvalho de. O Direito Ao Esquecimento Como Tutela Dos Direitos Da Personalidade Na Sociedade Da Informação: Uma Análise Sob A Ótica Do Direito Civil Contemporâneo. Revista Eletrônica Do Curso De Direito Da UFSM, v. 12, p. 218-236, 2017. http://dx.doi. org/10.5902/1981369424579 
DUBY, Georges. A History of Private Life: Revelations of the Medieval World (History of Private Life). Vol. II. Harvard: Belknap Press, 1993.

FACEBOOK. Política de Dados da Rede Social Facebook. Disponível em: www.facebook.com/about/privacy/]. Acesso em: 06 jan. 2020.

FERESTEIN, Gregory. Google's Cerf Says “Privacy May Be An Anomaly”. Historically, He's Right. Techcrunch. 2013. Disponível em: https://techcrunch.com/2013/11/20/googles-cerf-says-privacy-may-be-an-anomaly-historically-hes-right/. Acesso em: 04 jan. 2020.

FRANÇA, Rubens Limongi. Direitos da personalidade: coordenadas fundamentais. Revista dos Tribunais, São Paulo, v. 72, n. 567, p. 37, jan. 1983.

FRANKL, V. La voluntad de sentido. Barcelona: Herder, 1994.

GARCIA, Rafael de Deus. Os direitos à privacidade e à intimidade: origem, distinção, dimensões. Revista da Faculdade de Direito do Sul de Minas, Pouso Alegre, v. 34, n. 1: 1-26, jan./jun. 2018.

GHOSH, Shona. The power players behind Cambridge Analytica have set up a mysterious new data company. Business Insider. Disponível em: http://www.businessinsider.com/cambridge-analytica-executives-andmercerfamily-launch-emerdata-2018-3?r=UK\&IR=T. Acesso em 07 jan. 2020.

KELLER, David G. R. Oasis of Wisdom: The Worlds of the Desert Fathers and Mothers. Collegeville: Liturgical Press, 2005

LANE, Frederic S. American Privacy: The 400-Year History of Our Most Contested Right. Boston: Beacon Press, 2009.

MCDONALD, A. \& CRANOR, L. The Cost of Reading Privacy Policies. I/S: A Journal of Law and Policy for the Information Society, 4(3), 543-568, 2008.

MACEIRA, Irma Pereira. A proteção do direito à privacidade familiar na internet. Rio de Janeiro: Lumen Juris, 2015.

MARQUES, Cláudia Lima. Confiança no Comércio Eletrônico e a Proteção do Consumidor: um estudo dos negócios jurídicos de consumo no comércio eletrônico. São Paulo: Revista dos Tribunais, 2004.

MARTINS, G. G. Contratos Eletrônicos de Consumo. 3. ed. São Paulo: Atlas, 2016.

NASCIMENTO, Valéria Ribas do. Direitos fundamentais da personalidade na era da sociedade da informação: transversalidade da tutela à privacidade. Revista de informação legislativa: RIL, v. 54, n. 213, p. 265-288, jan./mar. 2017. Disponível em: http://www12.senado.leg.br/ril/edicoes/54/213/ril_v54_n213_p265.

OBAR, J. A.; OELDORF-HIRSCH, A. The biggest lie on the Internet: ignoring the privacy policies and terms of service policies of social networking services, Information, Communication \& Society, 2018, DOI: 10.1080/1369118X.2018.1486870.

PEIXOTO, E. L. C.; EHRHARDT JR., Marcos Augusto de A. Breves Notas sobre a Ressignificação da Privacidade. Revista Brasileira de Direito Civil - RBDCIVIL, v. 16, p. 35-56, 2018.

RODOTÀ, Stefano. A vida na sociedade da vigilância: a privacidade hoje. Tradução de Danilo Doneda e Luciana Cabral Doneda. Rio de Janeiro: Renovar, 2008.

SANTOS DIVINO, Sthéfano Bruno. Reflexiones escépticas, principiológicas y económicas sobre el consentimiento necesario para la recolección y tratamiento de datos. Derecho PUCP, n. 83, p. 179 - 206, 29 nov. 2019.

SARTORI, Ellen Carina Mattias. Privacidade e dados pessoais a proteção contratual da personalidade do consumidor na internet. Revista de Direito Civil Contemporâneo - RDCC: Journal of Contemporary Private Law, ISSN 2358-1433, No. 9, 2016, págs. 49-104.

SARTRE, J. P. in PROST, Antony; VINCENT, G. A History of Private Life: Riddles of Identity in Modern Times. Vol. 5. Cambridge: Harvard University Press, 1998.

SCHREIBER, A. Direitos da personalidade. 3. ed. São Paulo: Atlas, 2014.

SILVA, José Afonso da. Comentário contextual à Constituição. 5. ed. São Paulo: Malheiros, 2008. 
SOLOVE, Daniel J. Understanding privacy. Cambridge, London: Harvard University Press, 2008.

TEIXEIRA, A. C. B. Autonomia existencial. Revista Brasileira de Direito Civil - RBDCivil, v. 16, p. 75-104, 2018.

TUROW, Joseph; HENESSY, Michael; DRAPER, Nora. The tradeoff fallacy: how marketers are misrepresenting and opening them up to exploitation. Disponível em: https://www.asc.upenn.edu/sites/default/files/TradeoffFallacy_1.pdf. Acesso em: 06 jan. 2020.

WARREN, Samuel D.; BRANDEIS, Louis D. The Right to Privacy, Harvard Law Review, 1890.

WESTIN, Alan F. Privacy and Freedom. Nova York: IG Publishing, 2015.

Recebido/Received: 08.01.2020.

Aprovado/Approved: 08.06.2020. 